\title{
Erratum to: Pine Wilt Disease: a threat to European forestry
}

\author{
Cláudia Vicente • Margarida Espada • \\ Paulo Vieira $\cdot$ Manuel Mota
}

Published online: 31 March 2012

(C) KNPV 2012

\section{Erratum to: Eur J Plant Pathol \\ DOI 10.1007/s10658-011-9924-x}

Regarding the paper "Pine Wilt Disease: a threat to European forestry"(Vicente et al., 2012), the research was supported by the EC 7th Framework project REPHRAME (KBBE.2010.1.4-09, 'Analysis of the potential of the pine wood nematode (Bursaphelenchus xylophilus ) to spread, survive and cause pine wilt in European coniferous forests in support of EU plant health policy')

The online version of the original article can be found at http:// dx.doi.org/10.1007/s10658-011-9924-x.

C. Vicente $\cdot$ M. Espada $\cdot$ P. Vieira $\cdot$ M. Mota $(\bowtie)$

NemaLab/ICAAM, Universidade de Évora,

7002-554 Évora, Portugal

e-mail:mmota@uevora.pt 